\title{
Assessment of decorative features of lianas when using them for landscaping purposes of the Saratov-Engels agglomeration
}

\author{
Anna Kalmykova*, Yekaterina Guseva, and Alexandr Tereshkin \\ Saratov State Agrarian University named after N.I. Vavilov, Saratov, 410012, 1, Teatralnaya sq., \\ Russian Federation
}

\begin{abstract}
Currently, due to the intensive growth of cities, the area for landscaping is being reduced. In conditions of dense development, the use of vertical landscaping plays an important role. The selection of the assortment of plants, in addition to resistance to urban conditions, is also influenced by the decorative characteristics of the species. The use of vines for decorative purposes has a rich history. Along with utilitarian and sanitary-hygienic functions, lianas have long been used to decorate gardens. As a rule, aesthetic evaluation is subjective, but a number of signs can significantly affect its result. We evaluated the types of lianas by decorative qualities in the conditions of the Saratov-Engels agglomeration using the decorative scale. As a result of the study, various options for using lianas in landscaping according to their decorative qualities are proposed.
\end{abstract}

\section{Intoduction}

Modern cities, as a rule, have an established layout with a high density of buildings, where there is no possibility to accommodate traditional tree and shrub plantations. The negative impact on humans of unfavorable factors of the urban environment is reduced when green spaces are placed in the city $[1,2]$. Using of vertical landscaping plays an important role in conditions of dense development. The reasonable use of lianas in combination with traditional types of plantings will improve the quality indicators of the environment in settlements. The selection of the assortment of plants, in addition to resistance to urban conditions, is also influenced by the decorative characteristics of the species. The aim of this study to assess the decorative qualities of some types of lianas that have sufficient resistance to environmental conditions and to evaluate the prospects of their use in the Saratov landscaping.

\footnotetext{
* Corresponding author: nwuta80@mail.ru
} 


\section{Methods}

In the course of research, the historical aspect of the use of lianas for decorative purposes was studied. The study was conducted on the basis of the study of literary data and archival sources.

To study the decorative qualities of lianas in the conditions of the Saratov-Engels agglomeration, the following types of lianas were selected as objects of research: Parthenocissus quinquefolia (L.); Actinidia arguta Siebold\&Zucc.; Actinidia kolomikta Maxim.\&Rupr.; Schisandra chinensis Turcz.; Lonicera brownii (Regel) Carriere; Lonicera caprifolium L.; Clematis x jackmanii Th. Moore; Clematis tangutica (Maxim) Korsh.; Campsis radicans (L.) Seem. ex Bureau; Hydrangea petiolaris Siebold \& Zucc. The observed plants grow in green areas of limited use in the cities of Saratov and Engels, remote from sources of pollution. All the studied specimens grow in similar agrotechnical conditions: they are periodically cared for.

Based on the method of Balkovsky B.E. [3], used to compare the assortment by decorative qualities, a characteristic of lianas according to an expanded list of signs is proposed (Table. 1). Since when selecting an assortment for purposeful use, a detailed description of the decorative features of the species of lianas is important.

Table 1. Coding of decorative features of lianas.

\begin{tabular}{|l|c|}
\hline \multicolumn{1}{|c|}{ 1 } & 2 \\
\hline 1.1 Height of the liana & \\
\hline - creeping & \\
\hline - undersized (less than 5 m) & 1 \\
\hline - medium high (from 15 to 10 m) & 2 \\
\hline - high (from 20 to 15 m) & 3 \\
\hline - very high (more than 20 m) & 4 \\
\hline 1.2 The pattern of the crown & 5 \\
\hline - dense & \\
\hline - openwork & 1 \\
\hline 2. Trunk and shoots & 2 \\
\hline 2.1 The pattern of the trunk and shoots & \\
\hline - shoots are thin, weak, herbaceous & 1 \\
\hline - shoots are strong, woody, structural & 2 \\
\hline 2.2 Coloring of the trunk and shoots & \\
\hline - not decorative & 0 \\
\hline - original (white, silver-gray, light green, yellow, red, bronze, purple) & 1 \\
\hline 3. Leaves & \\
\hline 3.1 The timing of leaf blooming & \\
\hline - end of May & 0 \\
\hline - end of April - beginning of May & 1 \\
\hline - early April & 2 \\
\hline 3.2 Duration of leafing & \\
\hline - early leaf fall (early September) & 0 \\
\hline - average duration (September - October) & 1 \\
\hline - preservation of leaves before frost & 2 \\
\hline - throughout the year & 3 \\
\hline 3.3 Leaf size and shape & \\
\hline - large (20 - 40 cm), simple & 2 \\
\hline - large (20 - 40 cm), complex or dissected & 3 \\
\hline - medium (10 - 20 cm), simple & 4 \\
\hline - medium (10 - 20 cm), complex or dissected & \\
\hline
\end{tabular}




\begin{tabular}{|c|c|}
\hline - small $(5-10 \mathrm{~cm})$, simple & 5 \\
\hline - small $(5-10 \mathrm{~cm})$, complex or dissected & 6 \\
\hline - very small $(1-5 \mathrm{~cm})$, simple & 7 \\
\hline - very small $(1-5 \mathrm{~cm})$, complex or dissected & 8 \\
\hline \multicolumn{2}{|l|}{ 3.4 Leaf texture } \\
\hline - matte & 1 \\
\hline - glossy & 2 \\
\hline - pubescent & 3 \\
\hline \multicolumn{2}{|l|}{ 3.5 Leaf color } \\
\hline - dark green & 1 \\
\hline - green & 2 \\
\hline - light green & 3 \\
\hline - white-green & 4 \\
\hline - yellow-green, yellow & 5 \\
\hline - bluish-green & 6 \\
\hline - with shades of pink or red & 7 \\
\hline \multicolumn{2}{|l|}{ 3.6 Seasonal changes in leaf color } \\
\hline - the color does not change & 0 \\
\hline - the color changes when the leaves bloom & 1 \\
\hline - the color changes in autumn & 2 \\
\hline - the color changes throughout the season & 3 \\
\hline \multicolumn{2}{|l|}{ 3.7 Autumn leaf color } \\
\hline - not decorative & 0 \\
\hline - yellow and orange tones prevail & 1 \\
\hline - red tones prevail & 2 \\
\hline - purple tones prevail & 3 \\
\hline - green & 4 \\
\hline \multicolumn{2}{|l|}{ 4. Blossom } \\
\hline \multicolumn{2}{|l|}{ 4.1 The multiplicity of flowering } \\
\hline - lack of flowering & 0 \\
\hline - once per season & 1 \\
\hline - several times per season & 2 \\
\hline - a significant part of the growing season & 3 \\
\hline \multicolumn{2}{|l|}{ 4.2 Flowering dates } \\
\hline - early spring (April - early May) & 1 \\
\hline - spring (May) & 2 \\
\hline - spring - summer (end of May - June) & 3 \\
\hline - summer (end of June, July, August) & 4 \\
\hline - summer-autumn (August - September) & 5 \\
\hline - autumn (September - end of October) & 6 \\
\hline - a significant part of the growing season & 7 \\
\hline \multicolumn{2}{|l|}{ 4.3 Duration of flowering } \\
\hline - short-term (1-2 weeks) & 0 \\
\hline - average duration (up to 3 weeks) & 1 \\
\hline - long-term (up to 40 days) & 2 \\
\hline - long-term (41- 70 days) & 3 \\
\hline - a significant part of the growing season (more than 70 days) & 4 \\
\hline \multicolumn{2}{|l|}{ 4.4 The pattern of flowering } \\
\hline - single flowers & 1 \\
\hline - flowers are collected in inflorescences & 2 \\
\hline \multicolumn{2}{|l|}{ 4.5 The size of individual flowers } \\
\hline - small - up to $2 \mathrm{~cm}$ & 1 \\
\hline- medium $-2-5 \mathrm{~cm}$ & 2 \\
\hline- large $-5-10 \mathrm{~cm}$ & 3 \\
\hline
\end{tabular}




\begin{tabular}{|l|c|}
\hline - very large - more than $10 \mathrm{~cm}$ & 4 \\
\hline 4.6 The size of the inflorescences & 0 \\
\hline - no inflorescences & 1 \\
\hline - small - up to $10 \mathrm{~cm}$ & 2 \\
\hline - large - 10 - $20 \mathrm{~cm}$ & 3 \\
\hline - very large - $20-30 \mathrm{~cm}$ & \\
\hline 4.7 Flower coloring & 1 \\
\hline - white & 2 \\
\hline - yellow, pale yellow & 3 \\
\hline - pink, intense pink & 4 \\
\hline - orange, red & 5 \\
\hline - blue, purple, lilac & \\
\hline 4.8 Smell & 0 \\
\hline - missing & 1 \\
\hline - strong, unattractive & 2 \\
\hline - weak, unattractive & 3 \\
\hline - weak, pleasant & 4 \\
\hline - strong, pleasant & \\
\hline 5. Fruiting & \\
\hline 5.1 Duration of fruiting & 0 \\
\hline - fruits fall off quickly & 1 \\
\hline - fruits are preserved until winter & 2 \\
\hline - fruits are preserved until the next season & 3 \\
\hline - fruits and flowers are present at the same time & \\
\hline 5.2 The size and nature of fruiting & 1 \\
\hline - small (up to 3 cm) fruits, single & 2 \\
\hline - small (up to 3 cm) fruits, collected in brushes, bunches & 3 \\
\hline - medium (3 - 7 cm) fruits, single & 4 \\
\hline - medium (3 - 7 cm) fruits, collected in brushes, bunches & 5 \\
\hline - large (more than 7 cm) & 2 \\
\hline 5.3 Fruit coloring & 3 \\
\hline - black & 4 \\
\hline - white & 5 \\
\hline - straw yellow, yellow, orange & 6 \\
\hline - pink, red & 7 \\
\hline - dark cherry, purple & \\
\hline - blue & \\
\hline - green & \\
\hline & \\
\hline
\end{tabular}

With the help of digital characteristics of individual decorative features of liana species determined by the botanical description of the species based on the literature data, a digital polytonomic key was compiled. However, depending on the growing conditions, decorative features in lianas may not be fully manifested.

To assess the condition and manifestation of the decorative qualities of individual specimens of lianas in the conditions of the locality, the following scale is proposed (Table 2). It is based on the scale of Kalmykova A.L. [4]. We found it necessary to add point 3.5 to the assessment of decorative features, since the nature of leafing significantly affects the overall decorative quality of a liana specimen.

Table 2. Scale for assessing the decorative qualities of lianas for vertical gardening.

\begin{tabular}{|l|c|}
\hline \multicolumn{1}{|c|}{1} & 2 \\
\hline 1. General condition of the plant & \\
\hline - pronounced signs of depression, slowing of growth and development & 0 \\
\hline
\end{tabular}




\begin{tabular}{|c|c|}
\hline - mild signs of depression, slowing growth and development & 1 \\
\hline - no signs of oppression, good growth and development & 2 \\
\hline \multicolumn{2}{|l|}{ 1.2 The presence of dry shoots in the crown } \\
\hline - the proportion of the presence of dry shoots $>60 \%$ & 0 \\
\hline - the proportion of the presence of dry shoots is $30-60 \%$ & 1 \\
\hline - the proportion of the presence of dry shoots $<30 \%$ & 2 \\
\hline \multicolumn{2}{|l|}{ 1.3 The presence of damage } \\
\hline - the presence of various types of damage $>60 \%$ & 0 \\
\hline - the presence of various types of damage $30-60 \%$ & 1 \\
\hline - the presence of various types of damage $<30 \%$ & 2 \\
\hline - no damage & 3 \\
\hline \multicolumn{2}{|l|}{ 1.4 Crown development } \\
\hline - uneven & 1 \\
\hline - uniform & 2 \\
\hline \multicolumn{2}{|l|}{ 2. Trunk and shoots } \\
\hline \multicolumn{2}{|l|}{ 2.1 The pattern of the trunk and shoots } \\
\hline - shoots are thin, weak, herbaceous & 1 \\
\hline - shoots are strong, woody, structural & 2 \\
\hline \multicolumn{2}{|l|}{ 2.2 Coloring of the trunk and shoots } \\
\hline - not decorative & 0 \\
\hline - original (white, silver-gray, light green, yellow, red, bronze, purple) & 1 \\
\hline \multicolumn{2}{|l|}{ 3. Leaves } \\
\hline \multicolumn{2}{|l|}{ 3.1 The timing of leaf blooming } \\
\hline - end of May & 0 \\
\hline - end of April - beginning of May & 1 \\
\hline - early April & 2 \\
\hline \multicolumn{2}{|l|}{ 3.2 Duration of leafing } \\
\hline - early leaf fall (early September) & 0 \\
\hline - average duration (September - October) & 1 \\
\hline - preservation of leaves before frost & 2 \\
\hline - throughout the year & 3 \\
\hline \multicolumn{2}{|l|}{ 3.3 Seasonal changes in leaf color } \\
\hline - the color does not change & 0 \\
\hline - the color changes when the leaves bloom & 1 \\
\hline - color changes in autumn & 2 \\
\hline - color changes throughout the season & 3 \\
\hline \multicolumn{2}{|l|}{ 3.4 Autumn leaf color } \\
\hline - not decorative & 0 \\
\hline - yellow and orange tones prevail & 1 \\
\hline - red tones prevail & 2 \\
\hline - purple tones prevail & 3 \\
\hline - green & 4 \\
\hline \multicolumn{2}{|l|}{ 3.5 The nature of the leafing } \\
\hline - rare, extremely uneven & 0 \\
\hline - moderate, uneven & 1 \\
\hline - thick, uniform & 2 \\
\hline \multicolumn{2}{|l|}{ 4. Blossom } \\
\hline \multicolumn{2}{|l|}{ 4.1 The multiplicity of flowering } \\
\hline - lack of flowering & 0 \\
\hline - once per season & 1 \\
\hline - several times per season & 2 \\
\hline - a significant part of the growing season & 3 \\
\hline \multicolumn{2}{|l|}{ 4.2 Flowering dates } \\
\hline - early spring (April - early May) & 1 \\
\hline
\end{tabular}




\begin{tabular}{|c|c|}
\hline - spring (May) & 2 \\
\hline - spring - summer (end of May - June) & 3 \\
\hline - summer (end of June, July, August) & 4 \\
\hline - summer-autumn (August - September) & 5 \\
\hline - autumn (September - end of October) & 6 \\
\hline - a significant part of the growing season & 7 \\
\hline \multicolumn{2}{|l|}{ 4.3 Duration of flowering } \\
\hline - short-term (1-2 weeks) & 0 \\
\hline - average duration (up to 3 weeks) & 1 \\
\hline - long-term (up to 40 days) & 2 \\
\hline - long-term (41- 70 days) & 3 \\
\hline - a significant part of the growing season (more than 70 days) & 4 \\
\hline \multicolumn{2}{|l|}{ 4.4 Shape and size of flowers } \\
\hline - small, featureless & 0 \\
\hline - small, collected in inflorescences & 1 \\
\hline - medium-sized, expressionless & 2 \\
\hline - medium-sized, expressive shape & 3 \\
\hline - large, accent & 4 \\
\hline \multicolumn{2}{|l|}{ 4.5 Flowering intensity } \\
\hline - weak, single flowers & 0 \\
\hline - massive, uneven & 1 \\
\hline - mass, uniform & 2 \\
\hline \multicolumn{2}{|l|}{ 4.6 Contrast of color of flowers and leaves } \\
\hline - missing & 0 \\
\hline - weakly expressed & 1 \\
\hline - moderately pronounced & 2 \\
\hline - pronounced & 3 \\
\hline \multicolumn{2}{|l|}{ 4.7 Smell } \\
\hline - missing & 0 \\
\hline - strong, unattractive & 1 \\
\hline - weak, unattractive & 2 \\
\hline - weak, pleasant & 3 \\
\hline - strong, pleasant & 4 \\
\hline \multicolumn{2}{|l|}{ 5. Fruiting } \\
\hline \multicolumn{2}{|l|}{ 5.1 Fruiting intensity } \\
\hline - missing & 0 \\
\hline - single & 1 \\
\hline - medium intensity & 2 \\
\hline - mass & 3 \\
\hline \multicolumn{2}{|l|}{ 5.2 The size and nature of fruiting } \\
\hline - small (up to $3 \mathrm{~cm}$ ) fruits, single & 1 \\
\hline - small (up to $3 \mathrm{~cm}$ ) fruits, collected in brushes, bunches & 2 \\
\hline - medium $(3-7 \mathrm{~cm})$ fruits, single & 3 \\
\hline - medium $(3-7 \mathrm{~cm})$ fruits, collected in brushes, bunches & 4 \\
\hline - large (more than $7 \mathrm{~cm})$ & 5 \\
\hline \multicolumn{2}{|l|}{ 5.3 Decorative fruit } \\
\hline - unattractive & 0 \\
\hline - low - decorative & 1 \\
\hline - decorative & 2 \\
\hline \multicolumn{2}{|l|}{ 5.4 Contrast of foliage and fruits } \\
\hline - missing & 0 \\
\hline - weakly expressed & 1 \\
\hline - average & 2 \\
\hline - pronounced & 3 \\
\hline
\end{tabular}


The specimens of lianas that scored 36-57 points on this scale have a high decorative value, average $-18-35$ points, low $-2-17$ points.

\section{Results}

Climbing plants have been growing in gardens since the gardens themselves existed. Mentions of them are contained in descriptions of gardens and parks of Ancient Egypt, Assyria, Ancient Greece and Ancient Rome, Persia [5; 6; 7, 8, etc.]. An obligatory element of the layout of gardens has long been pergolas, gazebos, trellises, entwined with greenery. One of the first climbing plants included in the range of vertical gardening was the grape, or vine. There are many references to various types of ivy, climbing roses.

Gazebos called "coolers" appeared in Renaissance gardens. They were built from wooden slats and poles and planted with grapes. Long wide alleys of gardens at the villas were planted with trellises of climbing roses and other flowering plants. In the XVIXVIII centuries. trellises, entwined with lianas, became one of the main elements of the organization of space. In Italy during the Baroque era, the walls and niches of villas were full of sculptures and covered with climbing roses. In 17th-century Flanders, in Italian-style gardens, wooden trellises entwined with ivy or hops were used as solid walls of greenery [7]. Pylons covered with roses were popular in Europe from 1920 to 1950.

As a rule, lianas were cultivated for utilitarian purposes - harvesting fruits, harvesting medicinal raw materials, etc. However, this did not prevent them from being used as a "decorative" garden material. Thus, a decorative "grape garden" with many arbors entwined with lianas was created in the XVII century in Izmailovo. Maiden grapes plaits pergolas, retaining walls of stairs in Arkhangelsk. Arbors and "bersos" with honeysuckle caprifol were common in the parks of the XVIII century. From XVII to XX centuries . collections of botanical gardens and greenhouses in Russia were replenished by representatives of broad-leaved forests of the Far East, North America and the Caucasus [9].

The use of climbing plants is a classic gardening technique, including for historical objects of the Saratov province. The collections of lianas of manor gardens included a wide range of plants and were the pride of their owners: there were up to 180 varieties of "air roses" in the Bekovo estate of the Penza region. At the end of the XIX century. Art Nouveau contributed to the even greater popularity of lianas. From the description of the Marfino estate (Saratov province): "The flora is characterized by ... lianas enveloping the facades of buildings, pergolas and gazebos" [10].

Currently, the issue of the use of lianas for the purposes of landscaping settlements is becoming more and more relevant. The emphasis in the selection of species for urban green spaces shifts to sanitary and hygienic functions and decorative characteristics of the assortment.

Characterization of species using a polytonomical key facilitates the selection of plants with certain decorative qualities from an extensive assortment of lianas. Its use will make it possible to more effectively select an assortment of plants for the purposes of vertical landscaping of settlements. The dates, duration of flowering and other phenological periods in the table of decorative signs and in the key are given according to the average data of the results of observations of plants in Saratov and in Engels. The studied species complement the list of species considered in the work of Kalmykova A.L. (2009) [4]. 


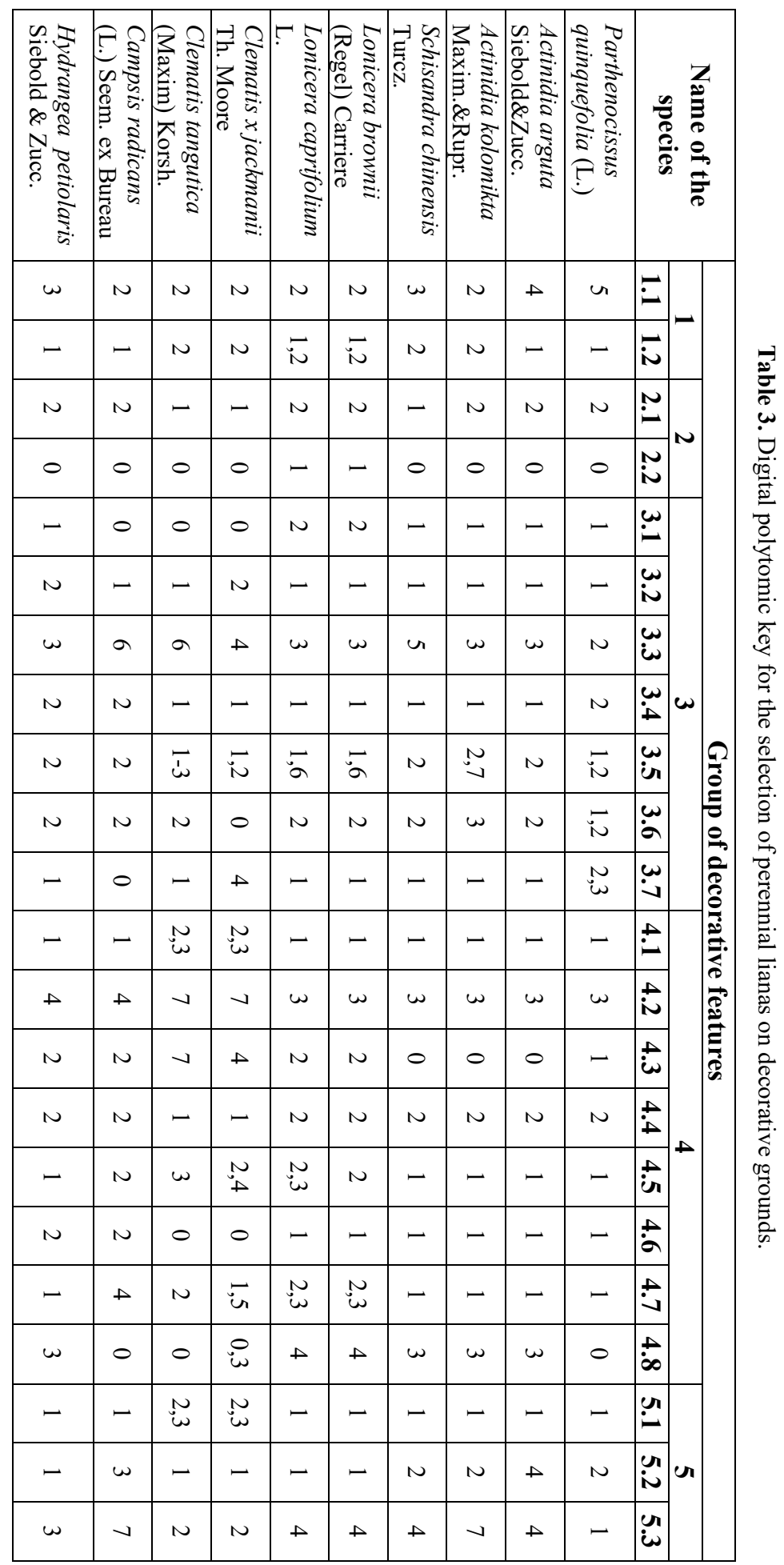


The average assessment of decorative liana species in Saratov is presented in Table 4.

Table 4. Decorative types of lianas in Saratov and Engels.

\begin{tabular}{|l|c|c|c|c|}
\hline \multirow{2}{*}{\multicolumn{2}{|c|}{ Name of the species }} & \multicolumn{4}{c|}{ Decorativeness of lianas in plantings } \\
\cline { 2 - 5 } & \multicolumn{2}{|c|}{ Saratov } & \multicolumn{2}{c|}{ Engels } \\
\cline { 2 - 5 } & score & degree & score & degree \\
\hline Parthenocissus quinquefolia L. & 31 & average & 33 & average \\
\hline Actinidia arguta Siebold\&Zucc. & 32 & average & 32 & average \\
\hline Actinidia kolomikta Maxim.\&Rupr. & 33 & average & 34 & average \\
\hline Schisandra chinensis Turcz. & 29 & average & 28 & average \\
\hline Lonicera brownii (Regel) Carriere & 40 & high & 41 & high \\
\hline Lonicera caprifolium L. & 44 & high & 44 & high \\
\hline Clematis x jackmanii Th. Moore & 41 & high & 42 & high \\
\hline Clematis tangutica (Maxim) Korsh. & 42 & high & 42 & high \\
\hline Campsis radicans (L.) Seem. ex Bureau & 37 & high & 39 & high \\
\hline Hydrangea petiolaris Siebold \& Zucc. & 41 & high & 42 & high \\
\hline
\end{tabular}

The data obtained make it possible to rank the lianas according to the degree of decorativeness (Fig. 1).

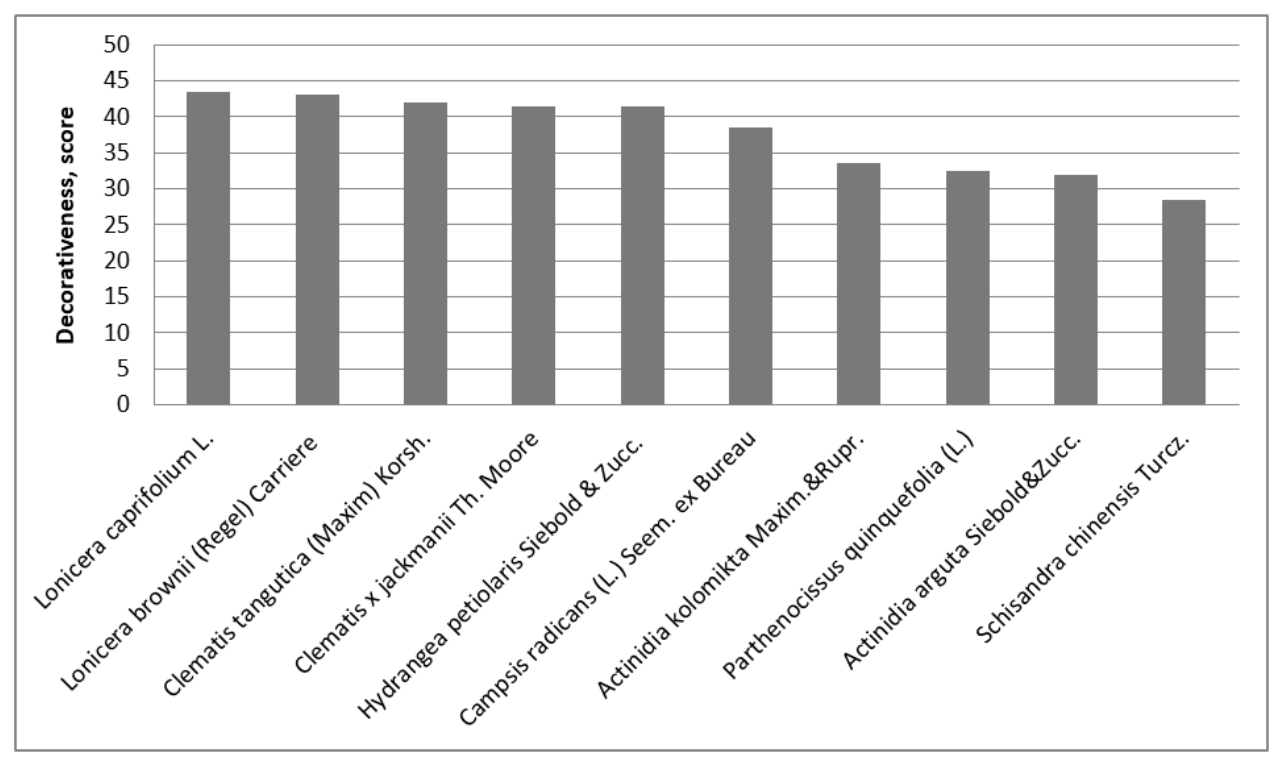

Fig. 1. Ranking of lianas according to the degree of decorativeness.

\section{Discussion}

The most decorative are the beautiful-flowering species: Clematis, Lonicera, Campsis radicans, Hydrangea petiolaris. Parthenocissus quinquefolia, Actinidia, and Schisandra chinensis are medium decorative. However, in some periods their indicators are higher than those of beautifully flowering plants, due to earlier leaf blooming, colorful autumn coloring or interesting fruits. The decorativeness of Parthenocissus quinquefolia and Lonicera is longer in time: their shoots are perennial and plants begin vegetation earlier. The decorative nature of plants also depends on the age of the latter: part of the decorative qualities begins to manifest itself only in adult plants. 
The construction of a composition with climbing plants must obey generally accepted laws. The task of vertical landscaping is to emphasize the individual character of the structure, highlight its individual parts, make them more expressive or, conversely, hide, decorate.

The lianas of medium texture should be dominant in the composition, as a rule, forming a background (Parthenocissus quinquefolia). Plants of rough texture (Amur and ordinary grapes) are recommended to be used where it is necessary to emphasize and strengthen a certain part of a building or structure compositionally. They are also suitable for creating the background of the composition (with a large area of landscaping, on large objects). Plants of fine texture (Clematis of various species, Lonicera brownii and Lonicera caprifolium, Schisandra chinensis, Actinidia) are recommended for use in the foreground of the composition and to soften its contours. Decorative compositions of lianas can be enhanced by the introduction of other plant life forms.

Great attention should be paid to factors such as abundant and prolonged flowering, decorative and duration of autumn coloring of leaves and fruits, leaf cover density, and the repair of flowering when selecting the types of lianas in the composition. Clematis, Lonicera, climbing Hydrangeas, and Campsis have the longest periods of decorativeness. Remontant flowering is noted in Lonicera brownii, the longest - in Clematis and Hydrangea.

Enhancing the decorative effect of planting perennial lianas can be achieved by including in the composition and planting annual species of climbing plants, as a rule, with high decorative properties. This technique will also allow you to vary the decoration over the years and get new unusual color and texture solutions [4].

\section{Conclusion}

Decorative characteristics of liana species in the conditions of the Saratov-Engels agglomeration generally correspond to the data given in literary sources. The studied plant specimens have medium (50\%) and high (50\%) decorative properties.

The selection of types of lianas for landscaping settlements should be carried out taking into account their decorative characteristics, periods and terms of achieving decorativeness. The following types of lianas can be recommended as accents in the composition: clematis of various species, Lonicera brownii and Lonicera caprifolium, Campsis, Hydrangea. To create background plantings, it is recommended to use Parthenocissus quinquefolia, Actinidia. To enhance the decorative effect and in order to create variability of plantings, annual species of lianas can be included in the compositions.

Types of lianas with dense foliage and a long period of decorativeness (Lonicera, Parthenocissus quinquefolia, Hydrangea) can be used to create a green sculpture on a frame, including in containers, which will allow you to diversify the appearance of urban green spaces and place them where the placement of traditional plantings is impossible.

\section{References}

1. R. Anguluri, P. Narayanan, Urban Forestry \& Urban Greening, 25 (2017)

2. M. Vuckovic, K. Kiesel, A. Mahdavi, Energy and Buildings, 145 (2017)

3. N.I. Denisov, Woody creepers of the Russian Far East (Diss. dokt. biological sciences, Vladivostok, 2004)

4. A.L. Kalmykova, The use of lianas in vertical gardening of settlements in the steppe of the Volga forest-steppe (Diss. candidate of agricultural sciences, Volgograd, 2008) 
5. M. Randhava, Gardens through the Ages (Moscow, Knowledge, 1981)

6. L.V. Zavadskaya, Vertical gardening (Moscow, Publishing House MSP, 2005)

7. N.V. Osipova, Lianas are amazing plants (Moscow, «Veche», 2005)

A. Medl, R. Stangl, F. Florineth, Building and Environment, 125 (2017)

8. L.S. Plotnikova, Creepers in your garden (Moscow, Kladez'-Buks, 2005)

9. O.B. Sokolskaya, Istoriya sadovo-parkovogo iskusstva (Moscow, INFRA-M, 2004) 